\title{
The Tropical Response to Extratropical Thermal Forcing in an Idealized GCM: The Importance of Radiative Feedbacks and Convective Parameterization
}

\author{
SARAH M. KANG ${ }^{*}$ \\ Program in Atmospheric and Oceanic Sciences, Princeton University, Princeton, New Jersey \\ DARGAN M. W. FRIERSON \\ Department of Atmospheric Sciences, University of Washington, Seattle, Washington \\ ISAAC M. HELD \\ NOAA/Geophysical Fluid Dynamics Laboratory, Princeton, New Jersey
}

(Manuscript received 18 August 2008, in final form 11 February 2009)

\begin{abstract}
The response of tropical precipitation to extratropical thermal forcing is reexamined using an idealized moist atmospheric GCM that has no water vapor or cloud feedbacks, simplifying the analysis while retaining the aquaplanet configuration coupled to a slab ocean from the authors' previous study. As in earlier studies, tropical precipitation in response to high-latitude forcing is skewed toward the warmed hemisphere. Comparisons with a comprehensive GCM in an identical aquaplanet, mixed-layer framework reveal that the tropical responses tend to be much larger in the comprehensive GCM as a result of positive cloud and water vapor feedbacks that amplify the imposed extratropical thermal forcing.

The magnitude of the tropical precipitation response in the idealized model is sensitive to convection scheme parameters. This sensitivity as well as the tropical precipitation response can be understood from a simple theory with two ingredients: the changes in poleward energy fluxes are predicted using a onedimensional energy balance model and a measure of the "total gross moist stability" $[\Delta m$, which is defined as the total (mean plus eddy) atmospheric energy transport per unit mass transport] of the model tropics converts the energy flux change into a mass flux and a moisture flux change. The idealized model produces a low level of compensation of about $25 \%$ between the imposed oceanic flux and the resulting response in the atmospheric energy transport in the tropics regardless of the convection scheme parameter. Because Geophysical Fluid Dynamics Laboratory Atmospheric Model 2 (AM2) with prescribed clouds and water vapor exhibits a similarly low level of compensation, it is argued that roughly $25 \%$ of the compensation is dynamically controlled through eddy energy fluxes. The sensitivity of the tropical response to the convection scheme in the idealized model results from different values of $\Delta m$ : smaller $\Delta m$ leads to larger tropical precipitation changes for the same response in the energy transport.
\end{abstract}

\section{Introduction}

One of the most prominent features of the tropical climate is the intertropical convergence zone (ITCZ). Small changes in the structure and position of the ITCZ

\footnotetext{
* Current affiliation: Climate Change \& Coastal Disaster Research Department, KORDI, Seoul, South Korea.

Corresponding author address: Sarah Kang, P.O. Box 29, Climate Change \& Coastal Disaster Research Department, KORDI, Ansan, Seoul 425-600, South Korea.

E-mail: skang.sarah@gmail.com
}

can produce large changes in local precipitation. Recent studies suggest that tropical precipitation can be influenced by extratropical forcing. For example, modeling studies show that the Atlantic ITCZ is displaced southward by freshwater input in the northern North Atlantic (Stouffer et al. 2006; Zhang and Delworth 2005). In addition, the ITCZ is shifted to the south when ice cover is increased in a general circulation model (GCM) at high northern latitudes (Chiang and Bitz 2005). Yoshimori and Broccoli (2008) have recently emphasized how aerosol cooling, concentrated in the Northern Hemisphere, shifts the ITCZ southward. These results indicate that cooling the high latitudes in one hemisphere can 
displace the ITCZ toward the opposite hemisphere. Moreover, paleoclimatic studies show a close relationship between tropical climate variations and high-latitude climate change-for example, records from the Cariaco Basin in the western tropical Atlantic covary with the ice core record in Greenland during the last glacial period and the Holocene (Peterson et al. 2000; Hughen et al. 2000). In particular, abrupt climate changes in Greenland associated with Dansgaard-Oeschger (DO) events are reflected in the tropical records (Lynch-Stieglitz 2004). Also, a 210-kyr record of wet periods of tropical northeastern Brazil is shown to be synchronous with cold periods in Greenland and Heinrich events in the North Atlantic (Wang et al. 2004).

The physical mechanism by which ITCZ displacements are forced from the extratropics is still unclear. One possible mechanism is suggested by Chiang and Bitz (2005), which involves changes in tropical sea surface temperature (SST) initiated by wind-evaporationSST feedback: high-latitude cooling is first spread over the entire high- and midlatitudes through transport and mixing - this extratropical cooling gives rise to anomalous easterlies in the subtropics-then these anomalous easterlies are superposed on preexisting easterlies, so that the surface wind speed increases. The result of this increased surface wind speed is increased evaporative cooling that pushes cold SST further equatorward; the ITCZ then responds to these cold SSTs. An alternative perspective is offered by Kang et al. (2008, hereafter K08), who examine an idealized experiment with an atmospheric model coupled to an aquaplanet slab ocean with a zonally symmetric lower boundary. In K08, changes in the ITCZ precipitation are forced by imposing antisymmetric interhemispheric heating in high latitudes, a similar experimental configuration to that of Broccoli et al. (2006). The focus in K08 is on the top-ofatmosphere (TOA) radiative fluxes and the associated atmospheric and oceanic energy transports; the magnitude of the ITCZ shift is related to changes in the atmospheric energy transport.

K08 also showed that the responses of the tropical precipitation and the energy transport are sensitive to aspects of the model physics that modify the cloud response, a key source of uncertainty in GCMs, implying that the tropical responses to the extratropical thermal forcing may be sensitive to model physics. For sufficiently complex systems such as comprehensive GCMs, it is necessary to understand how the dynamics change as key sources of complexity are added or subtracted (Held 2005). It is, thus, worthwhile to use intermediate complexity models that ignore cloud radiative feedbacks to better understand the changes in atmospheric energy transport and the connection between these changes in transport and the tropical precipitation. For instance, clouds being able to create significant gradients in the energy balance at the top of the tropical atmosphere, which would otherwise be small as a consequence of the small temperature gradients in the tropics, can mask the fundamental dynamical picture. In the present study, we use a moist GCM with simplified physical parameterizations and no water vapor or cloud feedbacks to radiation. Our intention here is not to try to simplify the model while retaining the quantitative response of the comprehensive model used in K08, but rather we hope to illustrate the importance of radiative feedbacks for this problem by showing how the results are modified very substantially in this simpler model. Eliminating water vapor and cloud-radiative feedbacks will also elucidate the purely dynamical response of the atmosphere to a change of the oceanic meridional energy transport. Moreover, the idealized model that we use has a relatively simple closure for moist convection with a small number of free parameters, which allows us to understand some ways in which details of a convection scheme can modify these results.

In section 2, the model and the experimental design are described. Section 3 discusses the result of simulations with high-latitude thermal forcing and its sensitivity to the convection scheme. In section 4, the response of the atmospheric energy fluxes is predicted using a diffusive energy balance model (EBM), which is then used to develop a theory that predicts the precipitation response. In section 5, we contrast the results from the idealized model with those obtained from a comprehensive atmospheric general circulation model. We conclude with section 6 .

\section{Model descriptions and experimental design}

The model employed in this study is the simplified moist GCM of Frierson et al. (2006), which provides a full description of the model, with the exception of the convection scheme that is described in Frierson (2007a). The model uses the primitive equations with T42 horizontal resolution and 25 vertical levels. The lower boundary is a zonally symmetric aquaplanet slab mixed layer ocean with a heat capacity of $1 \times 10^{7} \mathrm{~J} \mathrm{~m}^{-2} \mathrm{~K}^{-1}$, corresponding to $2.4 \mathrm{~m}$ of water. The results are not affected by the value of the mixed layer depth-for instance, the maximum tropical precipitation response (in Fig. 2d) increases only by $5 \%$, and the latitude of the maximum does not change, when the mixed layer depth is increased to $50 \mathrm{~m}$. So we choose a small heat capacity to reduce the time required for the model to reach equilibrium. The use of the slab ocean as the lower boundary ensures that the surface energy budget is closed. The 
simulations are run for four years, including two years of spin-up period.

One key element of the model physics is gray radiative transfer, in which radiative fluxes are only a function of temperature, meaning that water vapor and cloudradiative feedbacks are eliminated. The long-wave optical depths are a function of latitude and pressure, designed to approximate the effects of water vapor in the current climate; changes in water vapor content do not affect the radiative transfer. There are no clouds in the model. The short-wave heating approximates the observed annual and zonal mean net shortwave flux at the top of the atmosphere so there is no seasonal or diurnal cycle. For simplicity, all solar radiation is absorbed at the surface.

The convection parameterization is a simplified BettsMiller scheme, described fully in Frierson (2007a). BettsMiller convection schemes (Betts 1986; Betts and Miller 1986) relax temperature and humidity to postconvective equilibrium profiles over a specified relaxation time. For temperature, the convective reference profile $T_{\text {ref }}$ is a moist adiabat from surface parcels, which is later corrected to satisfy energy conservation, as in the original Betts-Miller formulation. For humidity, the reference profile $q_{\text {ref }}$ is a constant relative humidity $\left(\mathrm{RH}_{\mathrm{SBM}}\right)$ with respect to this moist adiabat. This form of humidity reference profile, also used in Neelin and Yu (1994), is simplified compared with the original Betts-Miller profile. The simplified Betts-Miller scheme is called whenever there is convective available potential energy (CAPE). If negative precipitation is ever predicted, shallow nonprecipitating convection occurs instead. The control value of $\mathrm{RH}_{\mathrm{SBM}}$ is $70 \%$, and the control value of the convective relaxation time is two hours.

The grid-scale condensation scheme in the model ensures that whenever the relative humidity of a grid box exceeds $100 \%$, condensation occurs to keep the grid box exactly at saturation. Grid-scale condensation is reevaporated into unsaturated grid boxes below, so grid-scale precipitation can only occur if the whole column is oversaturated. The fraction of precipitation that is handled through the large-scale condensation module can be modified by changing either of the convection scheme parameters: the convective relaxation time or $\mathrm{RH}_{\mathrm{SBM}}$. In section $3 \mathrm{~b}$, we vary $\mathrm{RH}_{\mathrm{SBM}}$ to examine the sensitivity of the tropical precipitation response to the convection scheme because Frierson (2007a) shows that the zonally averaged tropical circulation is strongly sensitive to the fraction of grid-scale precipitation versus convective precipitation.

The model used in section 5 is AM2, an atmospheric general circulation model developed at the Geophysical Fluid Dynamics Laboratory (GFDL). The details of the model are presented by Anderson et al. (2004), and the model configuration is the same as in K08. As in the simplified moist GCM, we consider aquaplanet simulations in which the atmosphere is coupled to a $2.4-\mathrm{m}$ thick slab mixed layer ocean. The model has no seasonal cycle of insolation but a diurnal cycle is retained. All the simulations are run for seven years, including three years of spin-up period. The convective closure in the model is a modified version of the relaxed ArakawaSchubert scheme of Moorthi and Suarez (1992). As in Arakawa and Schubert (1974), the convection consists of an ensemble of entraining plumes characterized by different lateral entrainment rates $\lambda$. The $\lambda$ 's are determined by computing the values needed to produce plumes that attain their levels of neutral buoyancy at each model level. In the AM2 implementation, deep convection is prevented from occurring in updrafts with a lateral entrainment rate $\lambda$ lower than a critical value $\lambda_{0}\left(=\alpha / z_{M}\right)$, where $z_{M}$ is the depth of the subcloud layer (Tokioka et al. 1988). This critical value $\lambda_{0}$ can be altered through the parameter $\alpha$ (0.025 in the standard model), which can influence a variety of tropical feedbacks (Held et al. 2007). With larger $\alpha$, the typical plume entrains more dry air as it ascends, losing buoyancy more rapidly when entraining, making it harder for deep convection to occur, and the fraction of large-scale condensation increases. In K08, a large sensitivity to the Tokioka parameter $\alpha$ is seen in the tropical precipitation response to high-latitude forcing. The sensitivity of the tropical response in AM2 is compared with the idealized GCM results in section 5.

The experiments are designed to perturb the distribution of tropical precipitation only by forcing high latitudes. As in K08, we impose cooling poleward of $40^{\circ} \mathrm{N}$ with equal and opposite heating added poleward of $40^{\circ} \mathrm{S}$. Experiments not described here suggest that the model responses are approximately linear, in that the response to this antisymmetric forcing can be thought of as the sum of the separate responses to high-latitude heating and cooling. The equation for the imposed flux $(H)$ is

$$
\begin{aligned}
& H=-A \sin \left[\frac{18}{5}\left(\theta+\frac{2 \pi}{9}\right)\right] \text { for }-\frac{\pi}{2}<\theta<-\frac{2 \pi}{9} \\
& H=-A \sin \left[\frac{18}{5}\left(\theta-\frac{2 \pi}{9}\right)\right] \text { for } \frac{2 \pi}{9}<\theta<\frac{\pi}{2}, \text { and } \\
& H=0 \text { otherwise, }
\end{aligned}
$$

where $\theta$ is latitude in radians and $A$ is the maximum amplitude of the forcing (in $\mathrm{W} \mathrm{m}^{-2}$ ). We use a series of values of $A=0,10,30,60$, and 90 . For reference, in the water hosing experiment by Zhang and Delworth 
(a)

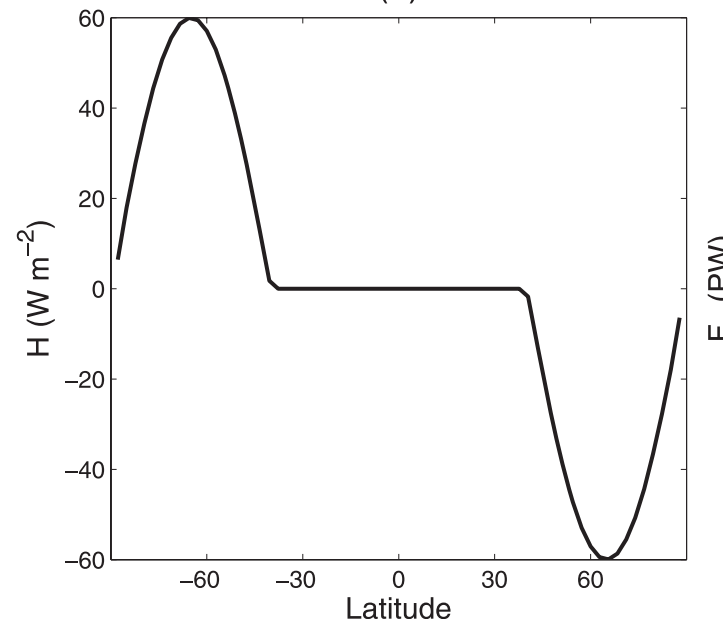

(b)

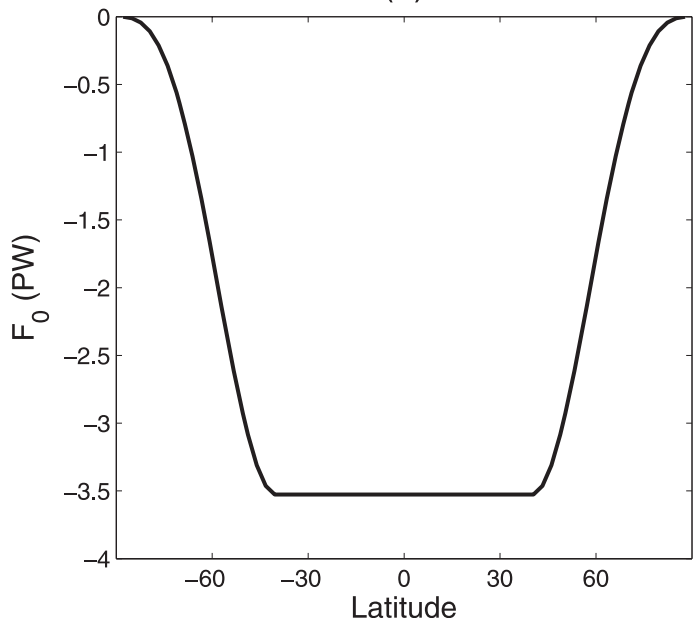

FIG. 1. (a) Latitudinal distribution of imposed oceanic fluxes $\left(H\right.$, in $\left.\mathrm{W} \mathrm{m}^{-2}\right)$ and (b) associated implied meridional oceanic heat transport $\left(F_{0}\right.$, in PW) with $H=-1 /\left(2 \pi a^{2} \cos \phi\right) \partial F_{0} / \partial \phi$ when $A=60 \mathrm{~W} \mathrm{~m}^{-2}$.

(2005), freshwater forcing of $0.6 \mathrm{~Sv}$ over the northern North Atlantic produces an anomalous horizontal heat transport convergence in the ocean of $10 \mathrm{~W} \mathrm{~m}^{-2}$ if spread uniformly over all longitudes and up to $120 \mathrm{~W} \mathrm{~m}^{-2}$ locally in the North Atlantic. Hence, the range of $A$ chosen in this study is somewhat large, but greater forcing is needed in this simplified GCM to create as much response as in a comprehensive GCM as a result of the lack of positive feedbacks from water vapor and clouds. Because the imposed forcing neither adds nor subtracts heat from the global system, the forcing $H$ can be integrated over latitude and longitude to be described in terms of an implied meridional oceanic heat transport $F_{0}$ with

$$
H=-\frac{1}{2 \pi a^{2} \cos \theta} \frac{\partial F_{0}}{\partial \theta},
$$

where $a$ is the radius of the earth. Distributions of $H$ and the associated oceanic heat transport $F_{0}$ are plotted in Fig. 1 . In these experiments, $F_{0}$ is negative, equivalent to a southward heat flux in the ocean. In section $3 a$, we find it useful to scale the change in atmospheric energy transport by the implied oceanic energy transport $F_{0}$.

\section{Results for the simplified moist GCM}

\section{a. Basic GCM experiments}

The extratropical thermal forcing induces responses not only in the extratropics but also in the tropics, as shown in Fig. 2. Displayed in Fig. 2a is the distribution of SST with latitude for different values of $A$ and the corresponding precipitation distribution in Fig. 2b. The differences from the control run $(A=0)$ in SST and precipitation are also shown in Figs. $2 \mathrm{c}$ and $2 \mathrm{~d}$, respectively. In the case of $A=90$, there is more than a $20-\mathrm{K}$ change in SST over high latitudes (Fig. 2c). As the amplitude of the external forcing gets larger, the precipitation is skewed more to the south with large local changes in mid- and high latitudes. The magnitude of the responses is roughly linear to the amplitude of the imposed forcing: the maximum precipitation change for $A=90$ is approximately 3 times larger than that for $A=30$. Maximum precipitation change occurs within the deep tropics (Fig. 2d) rather than in the extratropics where the forcing is imposed because of the sharp gradients in the tropical rainfall and its sensitivity to small displacement of the ITCZ. With this choice of parameters, the ITCZ response is weak; however, these model responses are a lower limit. We show in section $3 b$ that much larger tropical responses with more distinct ITCZ displacement can be obtained in this model with different convection scheme parameters.

The changes in tropical precipitation are closely related with the changes in the Hadley circulation. In response to extratropical forcing, the boundary between the two Hadley cells moves south of the equator, as shown in Fig. 3b, with a stronger cell in the cooled Northern Hemisphere and a weaker cell in the warmed Southern Hemisphere. Equivalently, the anomalous Hadley circulation displays clockwise circulation as in Fig. 3c, indicating southward mean moisture transport in the tropics. This southward moisture transport resulting from the anomalous Hadley circulation is consistent with the tropical precipitation being skewed to the south because changes in the mean moisture transport account for more than $85 \%$ of the tropical precipitation response. 
(a)

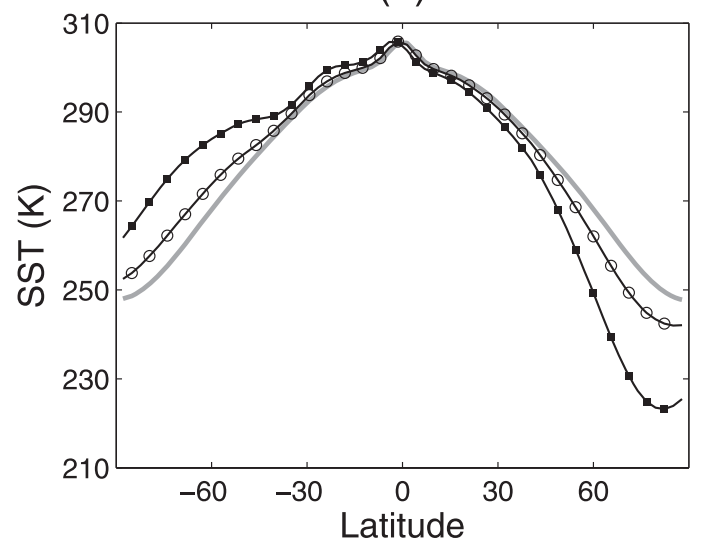

(c)

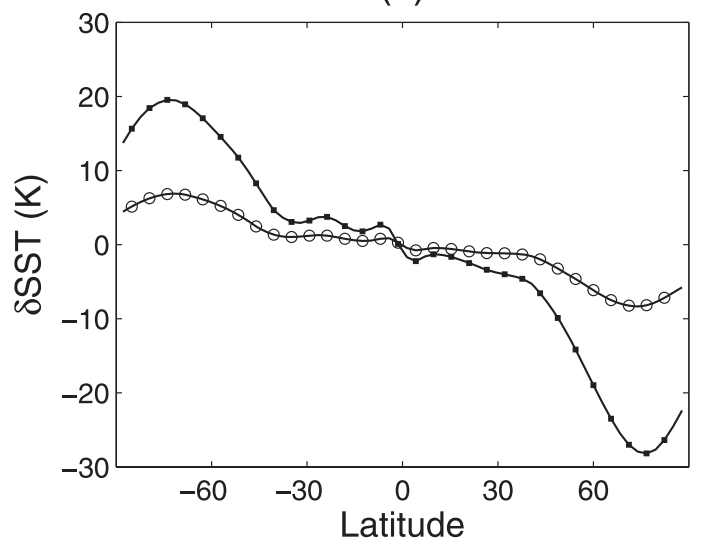

(b)

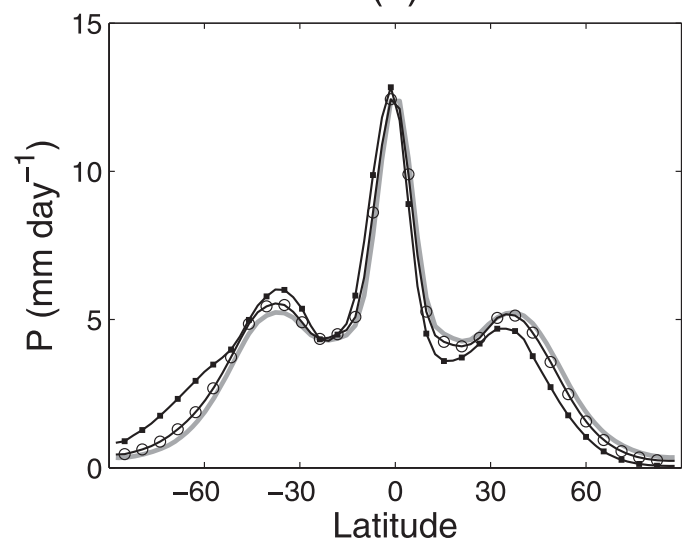

(d)

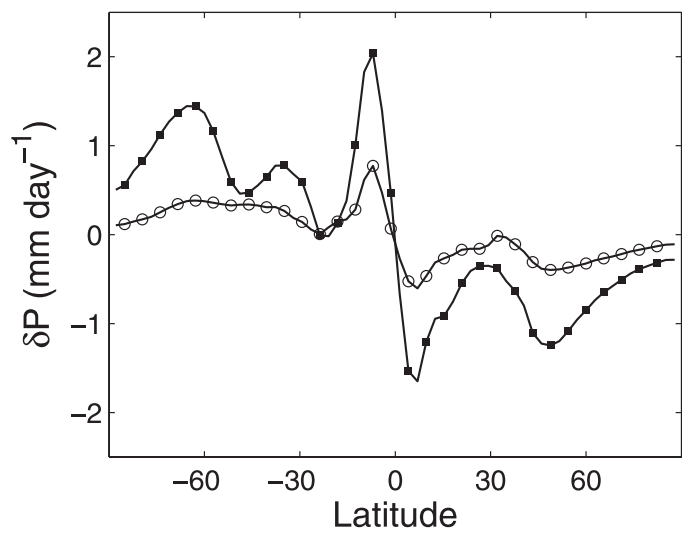

FIG. 2. Time mean, zonal mean (a) SST (K), (b) precipitation ( $\mathrm{mm} \mathrm{day}^{-1}$ ), (c) the change in SST (K), and (d) the change in precipitation ( $\mathrm{mm} \mathrm{day}^{-1}$ ) for $A=0 \mathrm{~W} \mathrm{~m}^{-2}$ (gray line), $A=30 \mathrm{~W} \mathrm{~m}^{-2}$ (black line with circles), and $A=90 \mathrm{~W} \mathrm{~m}^{-2}$ (black line with squares) where $A$ is the amplitude of the imposed forcing $H$.

Associated with the Hadley circulation mass flux response, the anomalous Hadley circulation in Fig. 3c transports moist static energy northward to compensate for part of the implied southward oceanic fluxes. If a larger fraction of the implied oceanic fluxes were to be balanced by atmospheric energy transport, then it would accompany stronger Hadley mass transport response, which would increase cross-equatorial moisture transport, thereby increasing the tropical precipitation response. Hence, one can expect that the magnitude of the tropical precipitation response is proportional to the fraction of the imposed forcing that is balanced by atmospheric meridional moist static energy fluxes. Thus, as in K08, we find it useful to define the degree of compensation $(C)$ between the resulting response in the atmospheric energy transport and the implied oceanic flux $F_{0}$ defined in Eq. (1). The steady-state energy budget for the atmosphere over a mixed layer, denoting zonal and vertical integral with a bracket and time mean with an overbar, is

$$
R_{\mathrm{TOA}}-\frac{1}{2 \pi a^{2} \cos \theta} \frac{\partial F_{0}}{\partial \theta}=\frac{1}{2 \pi a^{2} \cos \theta} \frac{\partial}{\partial \theta}\langle\overline{m v}\rangle
$$

where $R_{\mathrm{TOA}}$ is the zonal and time mean incoming net radiation at TOA, $F_{0}$ is the imposed meridional crossequatorial heat flux in the ocean, $m=C_{p} T+\Phi+L q$ is the moist static energy, and $v$ is the meridional velocity. In the definition of moist static energy, $\Phi$ is the geopotential height, $L$ is the latent heat of condensation, and $q$ is the specific humidity. We set $F=\langle\overline{m v}\rangle$, and the degree of compensation is defined as

$$
C=\left|\left(F-F_{\text {ctl }}\right) / F_{0}\right|,
$$

where the subscript ctl denotes the control case $(A=0)$.

The changes in atmospheric energy fluxes $F-F_{\text {ctl }}$ (solid line with circles) for the case $A=60$ are compared with the imposed oceanic flux $F_{0}$ (gray line) in Fig. 4. Because $F-F_{\text {ctl }}$ is very flat in the tropics, the degree of compensation varies little with latitude, with 
(a)

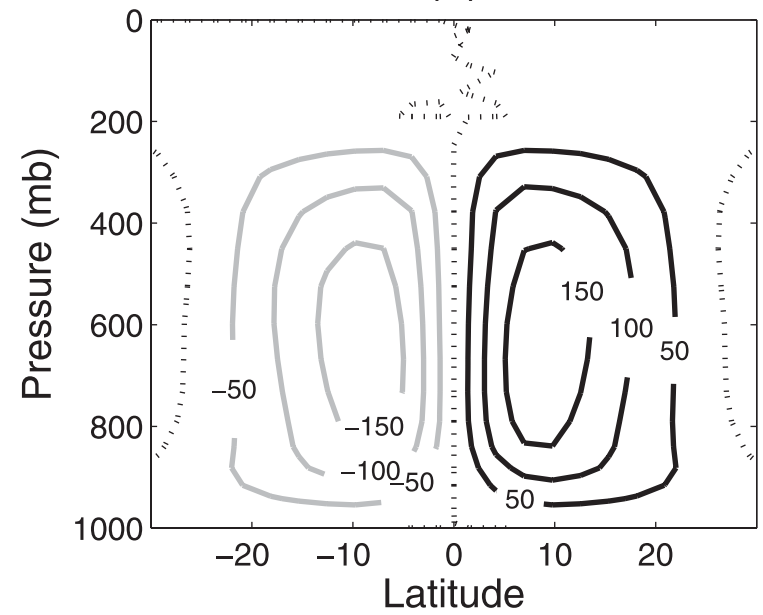

(b)

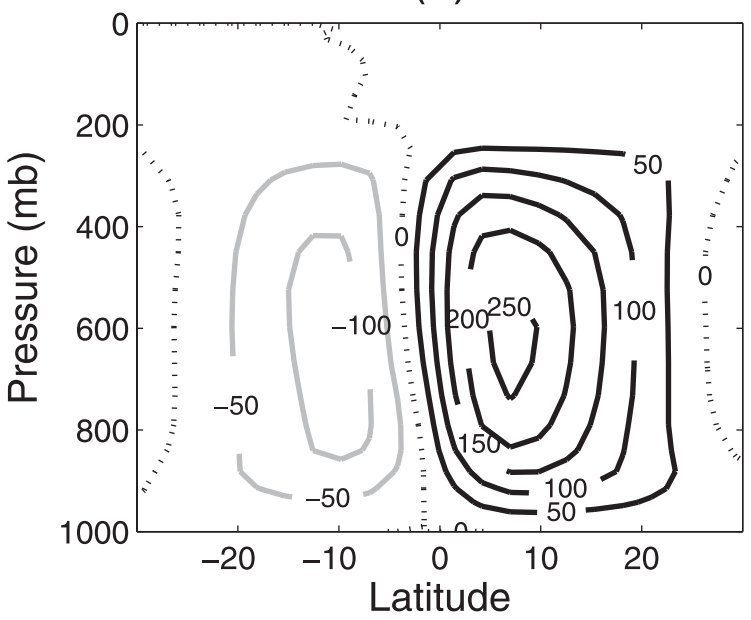

(c)

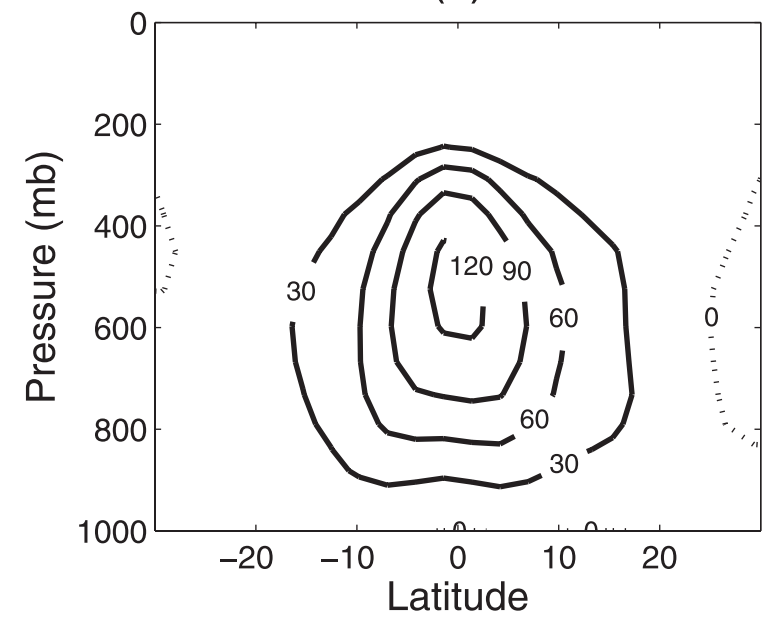

FIG. 3. Time mean, zonal mean streamfunction (in $10^{9} \mathrm{~kg} \mathrm{~s}^{-1}$ ) for (a) the control case $A=0 \mathrm{~W} \mathrm{~m}^{-2}$ and (b) $A=60 \mathrm{~W} \mathrm{~m}^{-2}$. (c) The change in time mean, zonal mean streamfunction for $A=$ $60 \mathrm{~W} \mathrm{~m}^{-2}$. Black (gray) contours correspond to clockwise (counterclockwise) circulation.

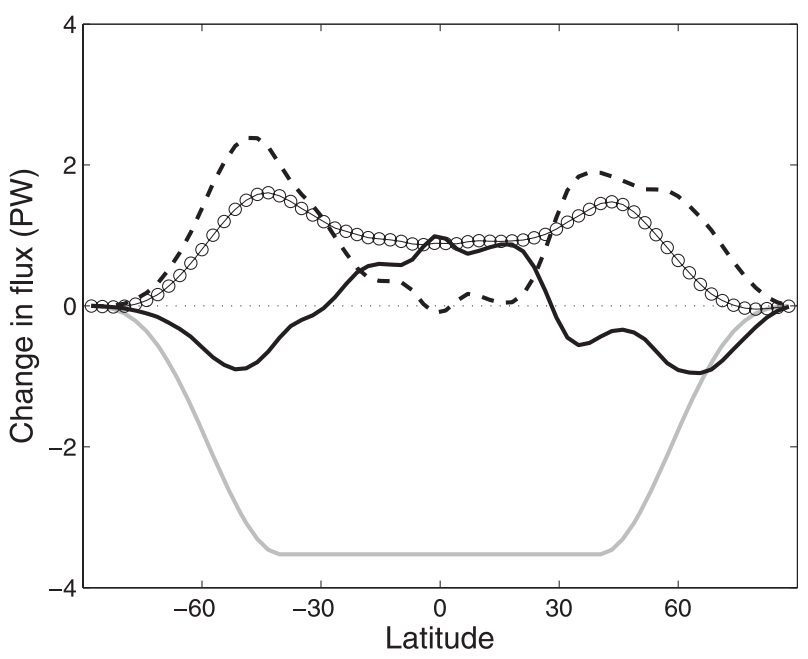

FIG. 4. The change in vertically integrated moist static energy transports, $F-F_{\text {ctl }}$ (in PW, solid line with circles), the anomalous mean energy transports (solid line), the anomalous eddy energy transports (dashed line), and the imposed oceanic flux, $F_{0}$ (gray line) for $A=60 \mathrm{~W} \mathrm{~m}^{-2}$.

an average value of $26 \%$ between $20^{\circ} \mathrm{S}$ and $20^{\circ} \mathrm{N}$. The gray line in Fig. 5 shows the degree of flux compensation averaged between $20^{\circ} \mathrm{S}$ and $20^{\circ} \mathrm{N}$ as a function of the amplitude $A$ for the model with the control convection scheme parameter $\mathrm{RH}_{\mathrm{SBM}}=70 \%$. Considering that the imposed oceanic fluxes differ by a factor of 9 , the difference of less than $5 \%$ in $C$ in cases with different $A$ shows that the response in energy fluxes increases proportionally with $A$.

To help understand the level of compensation of about $25 \%$, we first decompose $F-F_{\text {ctl }}$ into zonal mean and eddy parts (Fig. 4). As expected, the mean flow (solid line) dominates within the tropics, whereas the eddy part (dashed line) prevails in the extratropics. The maximum of the eddy response occurs at around $40^{\circ} \mathrm{N}$ and $40^{\circ} \mathrm{S}$. In response to cooling in the northern high latitudes, poleward eddy energy fluxes increase in a way to extract heat equatorward of $40^{\circ} \mathrm{N}$ and transport this energy poleward of $40^{\circ} \mathrm{N}$. This cooling created by eddies at the northern edge of the tropics has to be redistributed throughout the tropics by the Hadley circulation so as to maintain small tropical temperature gradients, because the tropical upper troposphere cannot sustain large horizontal temperature gradients due to the smallness of the Coriolis parameter (e.g., Sobel et al. 2001; Yano and Bonazzola 2009). Because the radiative fluxes in this model are a function of temperature only, the change in tropical energy fluxes must have small gradients in the tropics to avoid creating temperature gradients. In other words, the Hadley circulation responds to transport energy northward to distribute 


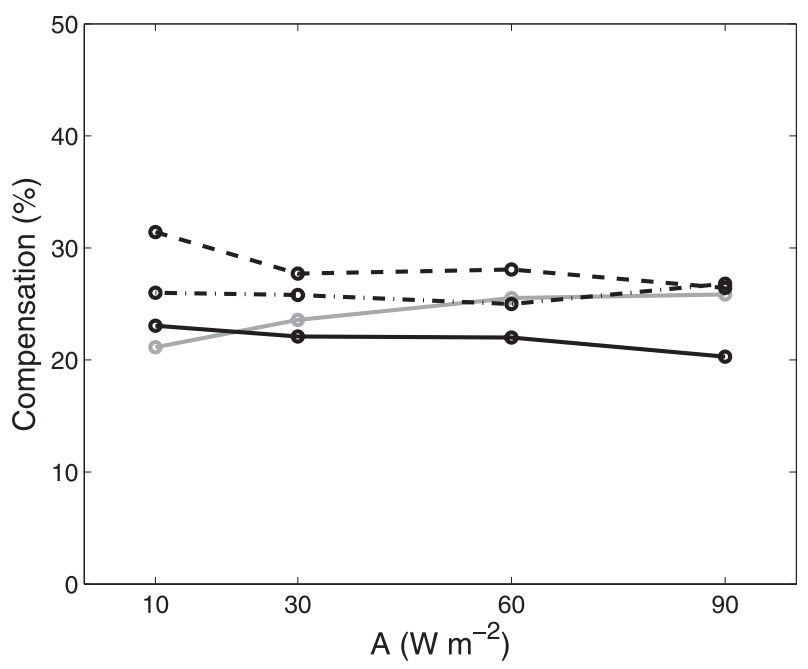

FIG. 5. The fraction of the imposed forcing that is balanced by the atmospheric energy flux averaged over $20^{\circ} \mathrm{S}$ and $20^{\circ} \mathrm{N}(C$ in \%) as a function of the strength of forcing $A$ for the idealized GCM with $\mathrm{RH}_{\mathrm{SBM}}=70 \%$ (gray solid line), $\mathrm{RH}_{\mathrm{SBM}}=85 \%$ (black dashed line), and $\mathrm{RH}_{\mathrm{SBM}}=100 \%$ (black solid line), and the energy balance model (black dashed-dotted line).

warming created by eddies in the southern subtropics to the northern subtropics where it is cooled by eddies. One can think of the compensation in the tropics as being determined by the response of the total energy fluxes near the edge of the tropics $\left(\sim 20^{\circ}-30^{\circ} \mathrm{N}\right.$ and $\left.\mathrm{S}\right)$. Thus, a theory for the degree of compensation in the tropics can be obtained from a theory for the response of the eddy energy fluxes at the edge of the tropical zone, assuming its perfect redistribution within the Hadley cell. This idea is tested using a diffusive energy balance model in section $4 \mathrm{a}$. This mechanism that determines $C$ is summarized in the schematic diagram in Fig. 6.

\section{b. Sensitivity to the convection scheme}

The study of Frierson (2007a) shows that the zonally averaged tropical circulation within this simplified GCM experiences large changes in response to changes in convection scheme parameters, specifically those that alter the fraction of convective precipitation versus gridscale precipitation. In addition to changes in the Hadley cell strength and tropical precipitation distribution, the speed of convectively coupled equatorial waves (CCEWs) is also significantly altered in such experiments (Frierson 2007b). In these two studies, the changes in circulation strength and CCEW speed are interpreted with the concept of "gross moist stability" (Neelin and Held 1987; Emanuel et al. 1994; Neelin 2007). When the gross moist stability is smaller, theoretical work suggests a stronger and narrower precipitating region (Bretherton and Sobel 2002; Chou and Neelin 2004), slower CCEWs (Neelin et al. 1987; Neelin and Yu 1994; Frierson et al. 2004), and a larger response to perturbations (Neelin and $\mathrm{Su}$ 2005; Chou et al. 2006). Thus, in this section, we study the response of the model to the convection scheme parameter $\mathrm{RH}_{\mathrm{SBM}}$, which changes the tropical gross moist stability.

As $\mathrm{RH}_{\text {SBM }}$ increases from $70 \%$ (the control value used in section 3a) to $85 \%, 90 \%$, and $100 \%$, the fraction of the rainfall in the tropics $\left(30^{\circ} \mathrm{S}-30^{\circ} \mathrm{N}\right)$ - that is, largescale in the model-increases from $0.5 \%$ to about $17 \%$, $83 \%$, and $100 \%$, respectively. The case with $\mathrm{RH}_{\mathrm{SBM}}=$ $100 \%$ is a model with large-scale condensation as the only convection scheme, which is referred to as the LSC-only case.

Figure 7 a shows the distribution of precipitation for the control case with different values of $\mathrm{RH}_{\mathrm{SBM}}$. With larger $\mathrm{RH}_{\mathrm{SBM}}$, there is a sharper ITCZ with the precipitation over the ITCZ enhanced and the subtropical precipitation decreased. This is associated with a stronger Hadley circulation mass transport, as shown in Frierson (2007a). The stronger Hadley cell transports more moisture into the tropics and results in greater precipitation in the deep tropics. It is important to note that although the Hadley circulation mass fluxes increase with increasing $\mathrm{RH}_{\mathrm{SBM}}$, the total energy transports $F_{\mathrm{ctl}}$ are similar in all cases.

We now turn our attention to the perturbed cases with extratropical thermal forcing. With larger $\mathrm{RH}_{\mathrm{SBM}}$, there is greater change in the precipitation distribution and an increase in the southward displacement of the ITCZ, as displayed in Fig. 7b. Increasing tropical precipitation response with $\mathrm{RH}_{\mathrm{SBM}}$ can be clearly seen in Fig. $7 \mathrm{c}$, which shows the anomalous precipitation when $A=60$. Note that in the LSC-only case, the precipitation response becomes asymmetric about the equator; that is, the zero crossing of precipitation response occurs off the equator (Fig. 7c). This asymmetry in precipitation response is associated with the asymmetric Hadley mass transport response. The measure of symmetry of the Hadley mass transport response is represented by

$$
\frac{\int_{0}^{20^{\circ} N} \delta \Psi(\theta, p) d \theta}{\int_{20^{\circ} S}^{20^{\circ} N} \delta \Psi(\theta, p) d \theta},
$$

where $\Psi(\theta, p)=\int_{P_{s}}^{P} v d p / g$ is the standard Eulerian meridional overturning streamfunction that is plotted in Fig. 3 and $\delta$ denotes the difference from the control run. The earlier quantity at $p=524 \mathrm{mb}$ is plotted in Fig. 8 . (Fifty percent indicates that the response of the Hadley mass transport is symmetric about the equator.) The 


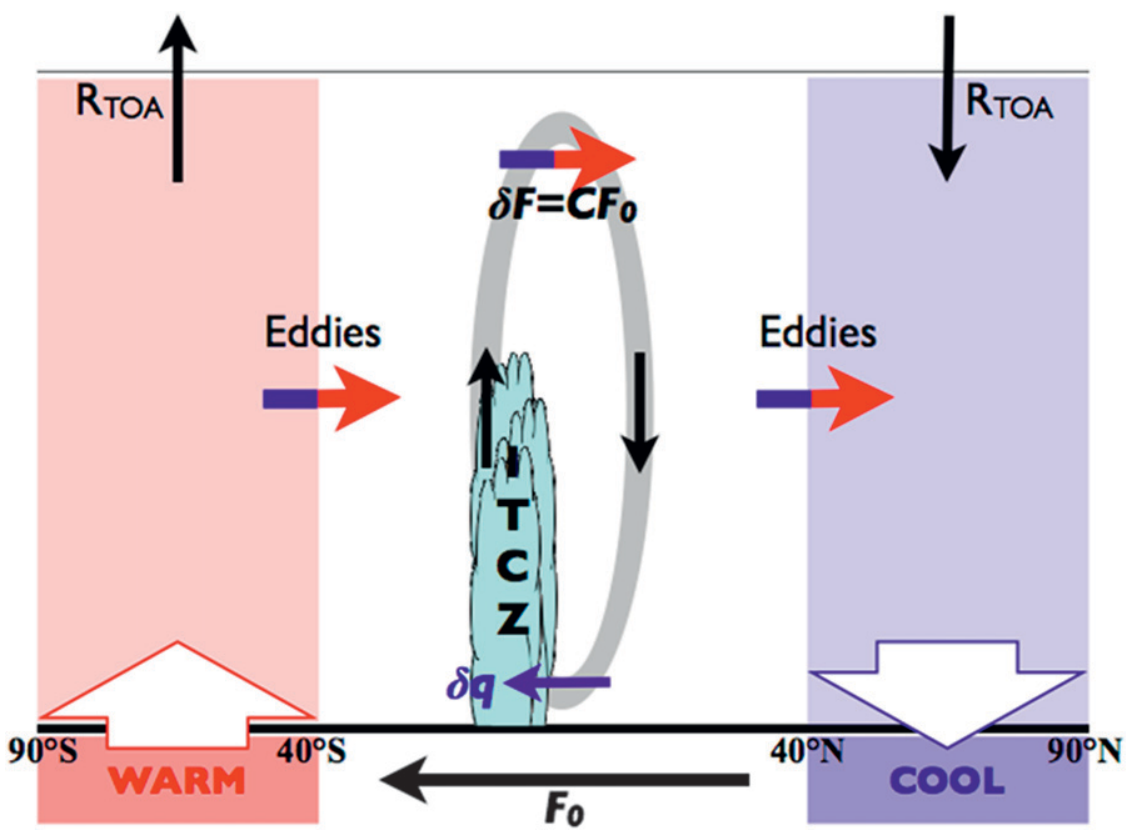

FIG. 6. Schematic of the mechanism that determines $C$. The gray oval indicates the anomalous Hadley circulation, of which the direction is denoted with black arrows. The blue (red) part of the arrow, which represents changes in atmospheric energy transports mostly by eddies at the edge of the tropics and by the Hadley circulation within the tropics, indicates cooling (warming). The clockwise anomalous Hadley circulation transports energy northward to cool (warm) the southern (northern) subtropics where it is warmed (cooled) by eddies. Hence, the compensation in the tropics is determined by the response of the total energy fluxes near the edge of the tropics $\left(\sim 20-30^{\circ} \mathrm{N}\right.$ or $\left.\mathrm{S}\right)$.

fraction is reduced abruptly from $50 \%$ when $\mathrm{RH}_{\mathrm{SBM}}$ approaches $90 \%$, consistent with the asymmetry of precipitation response for these cases.

In the K08 study, the sensitivity of the ITCZ response to physical parameters is related to changes in energy flux and compensation. However, in the simulations presented here, there is almost no change in energy flux: we obtain about the same amount of $C$ as $\mathrm{RH}_{\mathrm{SBM}}$ is varied, as shown in Fig. 5. Therefore, a theory for the different tropical precipitation responses in these cases must be based on something other than the energy budget.

\section{Prediction of the tropical precipitation responses}

\section{a. Energy balance model}

As the first step to predict the tropical precipitation response, we predict atmospheric energy fluxes from a one-dimensional (in latitude) EBM in which all of the energy transport is treated as a diffusion process (Sellers 1969) and impose the same oceanic heat fluxes $H$. A diffusive model is not a good approximation for the tropics but may be adequate for the extratropical fluxes that, in the image described in section $3 \mathrm{a}$, drive the tropical energy transports. As in Frierson et al. (2007), we diffuse moist static energy $(m)$, and the form of the energy balance model can be written as

$$
\mathrm{SW}-\mathrm{OLR}+H=-\frac{\tilde{D}}{a^{2} \cos \theta} \frac{\partial}{\partial \theta}\left(\cos \theta \frac{\partial m}{\partial \theta}\right),
$$

where SW is a prescribed solar radiation as in the idealized moist GCM. Here, OLR is assumed to be a linear function of the surface temperature $\left(T_{s}\right.$ in $\left.\mathrm{K}\right)$, OLR = $1.4 T_{s}-156$ (in $\mathrm{W} \mathrm{m}^{-2}$ ), which is the equation of the least squares regression line obtained from the control simplified moist GCM. The diffusion coefficient $\tilde{D}$ is related to the kinematic diffusivity $D$ by $\tilde{D}=p_{s} D / g$, where $p_{s} / g=10^{4} \mathrm{~kg} \mathrm{~m}^{-2}$, the mean mass of an atmospheric column per unit area. The value $D=9.5 \times$ $10^{5} \mathrm{~m}^{2} \mathrm{~s}^{-1}$ is obtained from the idealized GCM by averaging

$$
\left|-\frac{\frac{1}{\Delta p} \int_{p_{s}}^{0} \overline{m v} d p}{\left.\frac{1}{a} \frac{\partial m}{\partial \theta}\right|_{p_{s}}}\right|
$$


(a)

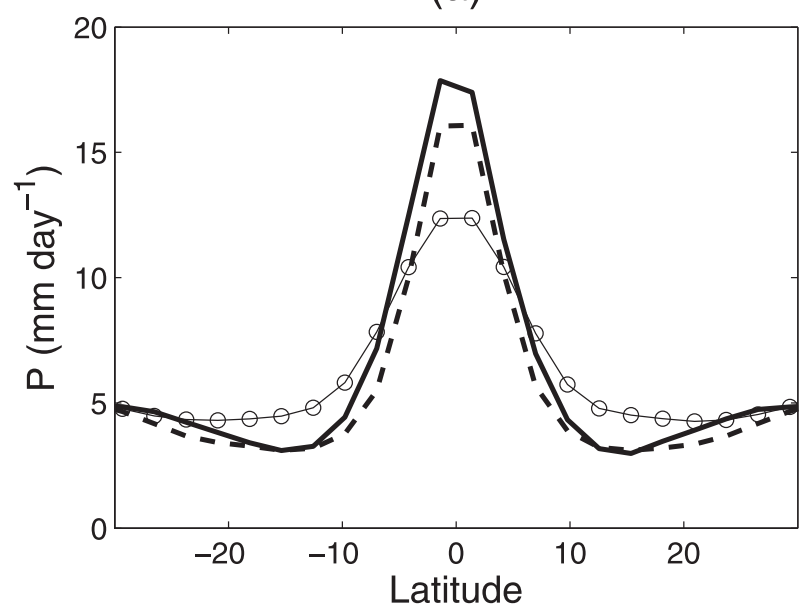

(b)

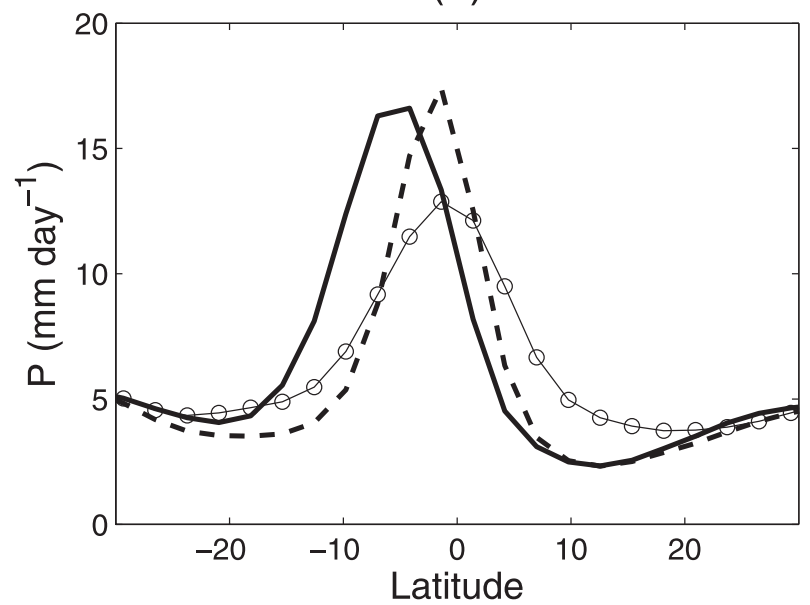

(c)

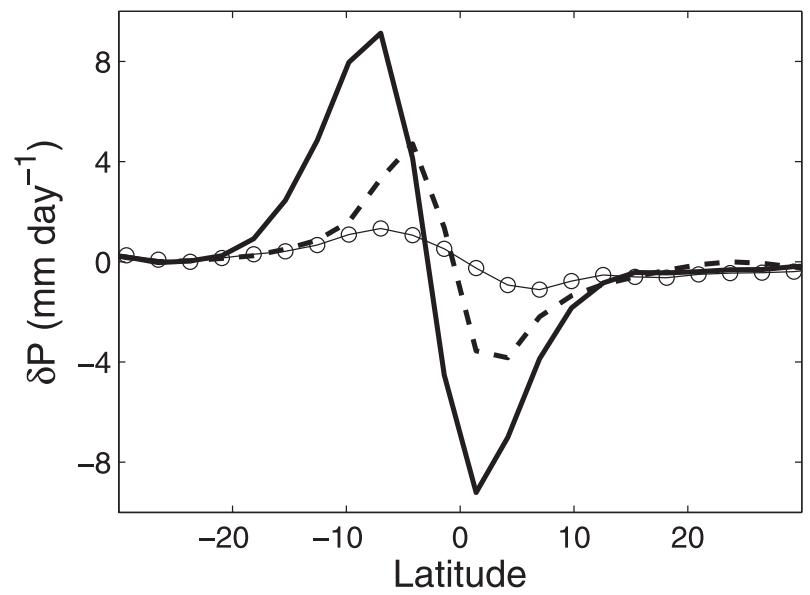

FIG. 7. Time mean, zonal mean precipitation $\left(\mathrm{mm} \mathrm{day}^{-1}\right)$ in the tropics for (a) the control runs $\left(A=0 \mathrm{~W} \mathrm{~m}^{-2}\right)$ and (b) $A=$ $60 \mathrm{~W} \mathrm{~m}^{-2}$, and (c) the anomalous time mean, zonal mean precipitation ( $\mathrm{mm} \mathrm{day}^{-1}$ ) when $A=60 \mathrm{~W} \mathrm{~m}^{-2}$ with $\mathrm{RH}_{\mathrm{SBM}}=70 \%$ (solid line with circles), $\mathrm{RH}_{\mathrm{SBM}}=85 \%$ (dashed line), and $\mathrm{RH}_{\mathrm{SBM}}=$ $100 \%$ (solid line).

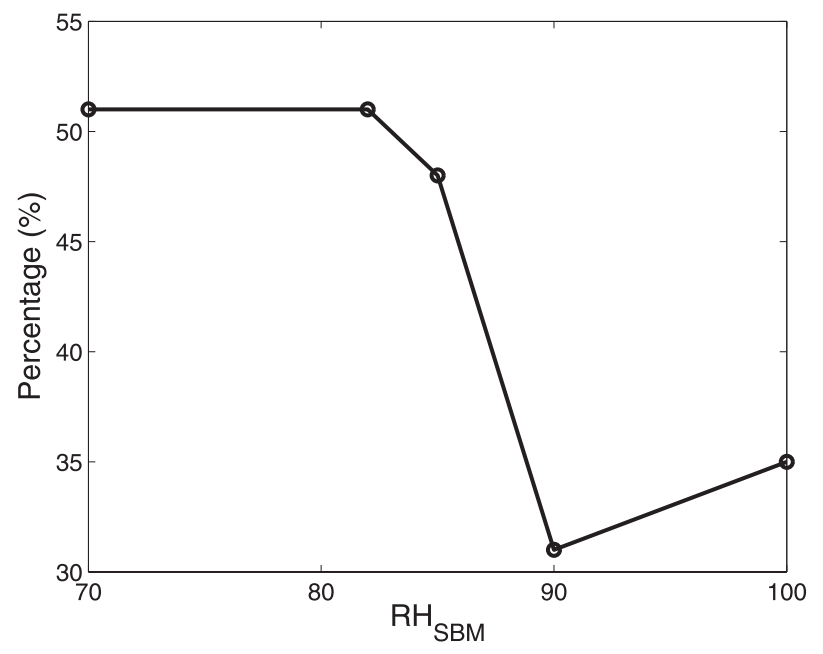

FIG. 8. The fraction of time mean, zonal mean streamfunction response between $20^{\circ} \mathrm{S}$ and $20^{\circ} \mathrm{N}$ at $524 \mathrm{mb}$ that is achieved in the Northern Hemisphere $\left(0^{\circ} \sim 20^{\circ} \mathrm{N}\right)$ when $A=60 \mathrm{~W} \mathrm{~m}^{-2}$ as a function of $\mathrm{RH}_{\mathrm{SBM}}$. Here, $50 \%$ indicates the Hadley circulation response is symmetric about the equator in terms of mass transport.

over latitudes poleward of $40^{\circ} \mathrm{N}$ and $\mathrm{S}$ in the control case, where $\Delta p$ is the pressure depth of the troposphere. As in Frierson et al. (2007), we take $m$ to be the moist static energy just above the surface, which can be written as

$$
m=C_{p} T_{s}+L_{v} q_{s}=C_{p} T_{s}+L_{v} h_{s} q_{s}^{*}=C_{p} T_{s}+L_{v} h_{s} \frac{R_{d} e_{s}^{*}}{R_{v} p_{s}}
$$

where $T_{s}$ is the surface temperature, $q_{s}^{*}$ is the saturation specific humidity at the surface, $h_{s}$ is the surface relative humidity (fixed as $76 \%$ ), and $e_{s}^{*}$ is the saturation vapor pressure calculated using $T_{s}$ in the Clausius-Clapeyron equation. Because both OLR and $m$ are a function of $T_{s}$ and SW, $H$, and $D$ are prescribed, one can solve Eq. (3) for $T_{s}$.

From Eq. (3), the atmospheric energy transport $F$ in the EBM can be obtained as

$$
F=-2 \pi \tilde{D} \int_{\theta} \frac{\partial}{\partial \theta}\left(\cos \theta \frac{\partial m}{\partial \theta}\right) d \theta
$$

Figure 9 compares the predicted $F$ using the EBM given $D$ and the actual $F$ in the simplified moist GCM for cases with $A=0$ and $A=60$. Both the magnitude and the position of the maximum $F$ agree very well, as does the change in atmospheric energy fluxes (Fig. 9c). Further, there is about the same degree of compensation in the EBM as in the idealized moist GCM for the entire range of forcing amplitudes considered, as compared in Fig. 5. Hence, given the diffusivity in the control run, an 
(a)

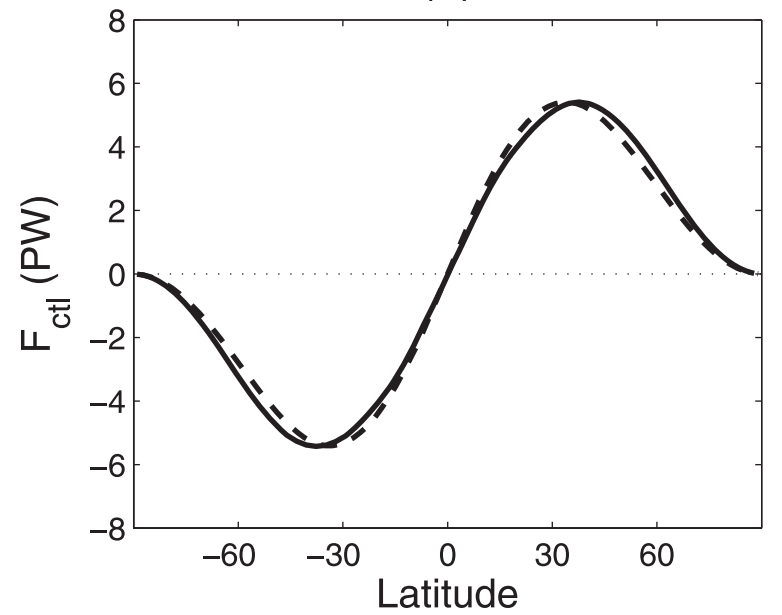

(b)

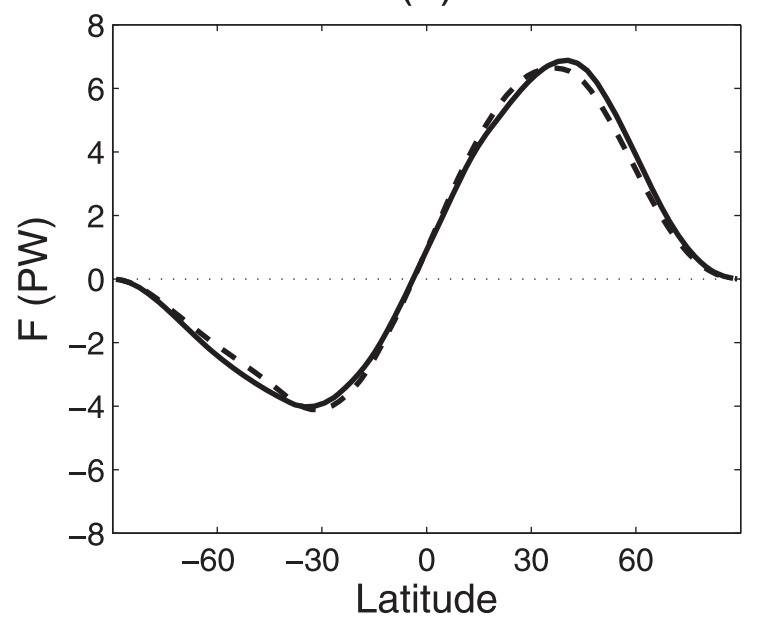

(c)

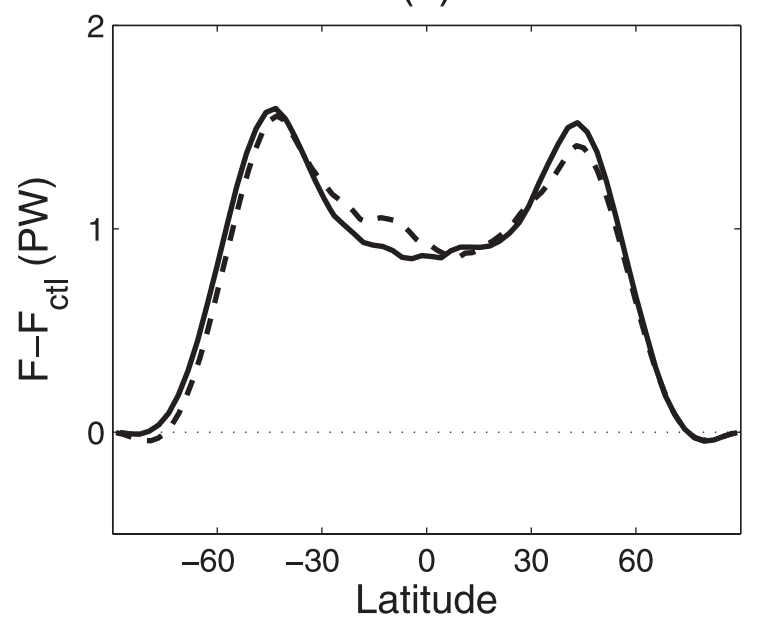

FIG. 9. The vertically integrated moist static energy transports $F$ (PW) for (a) $A=0 \mathrm{~W} \mathrm{~m}^{-2}$ and (b) $A=60 \mathrm{~W} \mathrm{~m}^{-2}$, and (c) the anomalous vertically integrated moist static energy transports, $F-F_{\text {ctl }}(\mathrm{PW})$ for $A=60 \mathrm{~W} \mathrm{~m}^{-2}$ in the simplified moist GCM (solid line) and the energy balance model (dashed line). energy balance model can be used to predict the compensation percentage. The implication is that the response of tropical atmospheric energy fluxes is determined primarily by the communication between the extratropics and the Hadley cell through eddy energy transport. The larger the diffusivity $D$, the more energy is extracted from the tropics by diffusion, the larger the energy that has to be distributed by the Hadley circulation in the tropics, leading to a larger degree of compensation. Because the diffusivity $D$ changes little as we vary $\mathrm{RH}_{\mathrm{SBM}}$, the compensation $C$ is insensitive to $\mathrm{RH}_{\text {SBM }}$ (Fig. 5).

\section{b. Theory for the tropical precipitation response}

We now show how energy fluxes predicted from the EBM (given the value of diffusivity from the idealized GCM) can be used to predict tropical mass flux response, which can then be used to develop a theory for the precipitation response. This theory predicts the response of tropical precipitation to high-latitude forcing, and it also captures the sensitivity to $\mathrm{RH}_{\mathrm{SBM}}$. The theoretical arguments developed here follow in spirit the moist static energy budget arguments reviewed in Neelin (2007) and its accompanying literature.

In an equilibrium state, the precipitation can be decomposed into evaporation and moisture convergence. The response of each term is illustrated in Fig. 10 for the case with $A=60$ and control $\mathrm{RH}_{\mathrm{SBM}}$. The dominant term in the response of precipitation $\delta \bar{P}$ is anomalous moisture convergence $\delta\langle-\nabla \cdot \overline{q v}\rangle$. Thus, the evaporation response is neglected and the tropical precipitation response is approximated as

$$
\delta \bar{P} \approx-\delta \nabla \cdot\langle\overline{q v}\rangle .
$$

This approximation works for all other cases with different values of $A$ and $\mathrm{RH}_{\mathrm{SBM}}$ as well. We now define the "total gross moisture stratification":

$$
\Delta q \equiv-\frac{\langle\overline{q v}\rangle}{v_{2}}
$$

where $v_{2}=\int_{p_{s}}^{p_{m}} \bar{v} d p / g$. Here, $v_{2}$ is the mass flux in the lower layer, with $p_{s}$ as the surface pressure and $p_{m}$ as some midtropospheric level where a vertically integrated mass flux attains its maximum ( $p_{m}$ generally falls between 700 and $550 \mathrm{mb}$ ). Specifically, $\Delta q$ measures how much moisture is transported given the mass transport in the lower atmosphere, that is, the total moisture transport per unit mass transport; $\Delta q$ is similar to the gross moisture stratification in Neelin and Yu (1994), except that eddy moisture transport is accounted for as well. Using $\Delta q$, Eq. (4) can be written as $\delta \bar{P} \approx \delta \nabla \cdot\left(v_{2} \Delta q\right)$, 


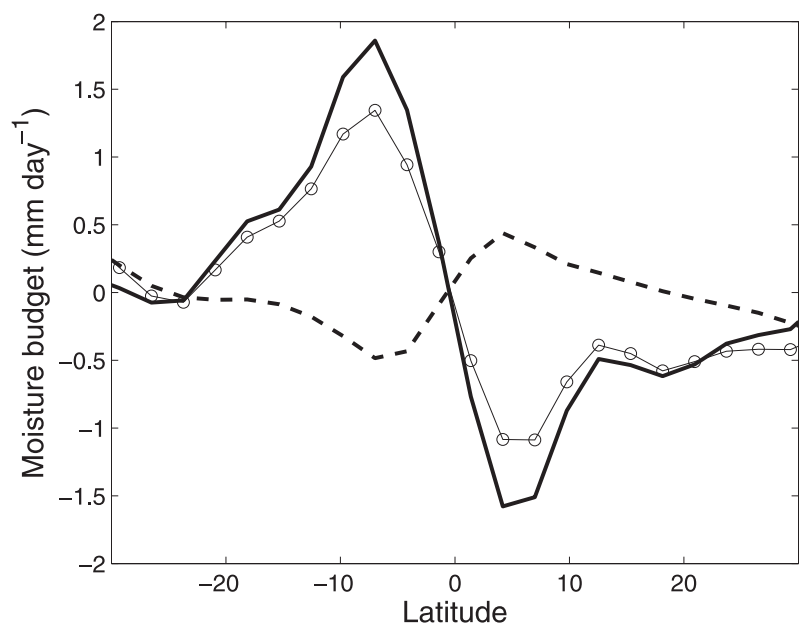

FIG. 10. The anomalous precipitation, $\delta \bar{P}$ (solid line with circles), the anomalous moisture convergence, $-\delta\langle\nabla \cdot \overline{q v}\rangle$ (solid line), and the anomalous evaporation, $\delta \bar{E}$ (dashed line) for the case when $A=60 \mathrm{~W} \mathrm{~m}^{-2}$ with $\mathrm{RH}_{\mathrm{SBM}}=70 \%$ (units are $\mathrm{mm} \mathrm{day}^{-1}$ ).

and this can be further approximated by taking $\Delta q$ of the control run $(A=0) \Delta q_{\mathrm{ctl}}$ :

$$
\delta \bar{P} \approx \nabla \cdot\left(\Delta q_{\mathrm{ctl}} \delta v_{2}\right)
$$

because the changes in $\Delta q$ in response to the highlatitude forcing are small. The approximation by Eq. (5) and the actual precipitation response are compared in Fig. 11 for the case $A=60$ with $\mathrm{RH}_{\mathrm{SBM}}=70 \%$. This approximation works equally well for all other cases with different values of $A$ and $\mathrm{RH}_{\mathrm{SBM}}$. The use of the total moisture flux, rather than the mean moisture flux, in this analysis has a very modest effect on the results; we include it here for consistency with the inclusion of eddy moisture flux in the energy flux, as described later.

The next step in explaining the precipitation response is to obtain the mass flux response. The appropriate quantity to consider to predict the response of mass fluxes $\delta v_{2}$ is what we call the "total gross moist stability," defined as $\Delta m \equiv F / v_{2}$, where $F=\langle\overline{m v}\rangle$. Here, $\Delta m$ measures the total atmospheric energy transported per unit mass transport; $\Delta m$ is similar to the gross moist stability in Neelin and Held (1987) but follows Frierson (2007a) in defining it by a ratio of fluxes rather than flux divergences, this being more convenient in the zonally symmetric case. In addition, unlike Frierson (2007a), the eddy energy transport as well as the mean energy transport is included. The eddy energy flux in the tropics is dominated by the flux of latent heat. Although the inclusion of the eddy flux makes little difference in the estimation of the total gross moisture stratification $\Delta q$ earlier, it does have a significant effect on the estimation of this total gross moist stability. The total energy flux is

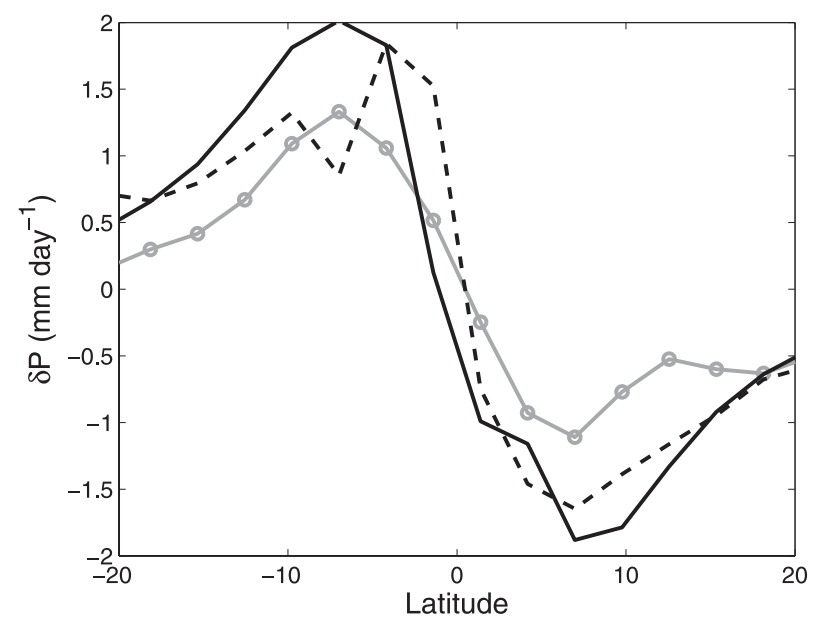

FIG. 11. The anomalous precipitation (gray solid line with circles), its approximation $-\nabla \cdot\left(\Delta q_{\mathrm{ctl}} \delta v_{2}\right)$ (black dashed line), and its full prediction from the imposed oceanic flux $\left(F_{0}\right)$ and the degree of compensation $(C=25 \%) \nabla \cdot\left(\Delta q_{\mathrm{ctl}} / \Delta m_{\mathrm{ctl}} C F_{0}\right)$ (black solid) for the case when $A=60 \mathrm{~W} \mathrm{~m}^{-2}$ with $\mathrm{RH}_{\mathrm{SBM}}=70 \%$ (units are mm day ${ }^{-1}$ ).

more robust and behaves more simply than the mean component in isolation throughout the simulations. In particular, the total flux response can be predicted using one number $C=25 \%$, as we have seen. Assuming that the $\Delta m$ response to high-latitude forcing is negligible, from the definition of $C$ in Eq. (2) the mass flux response can be predicted as

$$
\delta v_{2} \approx \frac{\delta F}{\Delta m_{\mathrm{ctl}}} \approx \frac{C F_{0}}{\Delta m_{\mathrm{ctl}}} .
$$

Equation (6) implies that the reduction in $\Delta m_{\mathrm{ctl}}$ with increasing $\mathrm{RH}_{\mathrm{SBM}}$ leads to a larger response in the Hadley circulation mass transport because the energy transport response $(C)$ is similar. The predicted response from Eq. (6) is symmetric about the equator by construction, so that this prediction does not work as well for the cases with asymmetric mass transport response that results when $\mathrm{RH}_{\mathrm{SBM}}$ is greater than $90 \%$, as shown in section $3 b$.

Substituting the predicted $\delta v_{2}$ from Eq. (6) in Eq. (5), the response of precipitation can be as approximated as

$$
\delta \bar{P} \approx \nabla \cdot\left(\frac{\Delta q_{\mathrm{ctl}}}{\Delta m_{\mathrm{ctl}}} C F_{0}\right) .
$$

The prediction by Eq. (7) is compared with the actual anomalous precipitation in Fig. 11. The predicted distribution of $\delta \bar{P}$ has almost the same shape as the actual response, although local minima and maxima are overpredicted. Considering the simplicity of the theory, it does well at capturing the gross features such as the 


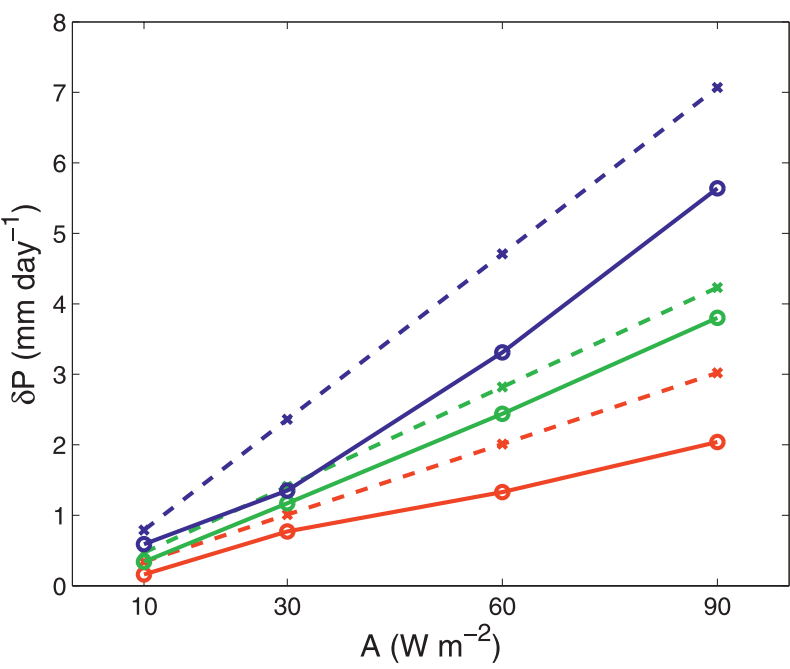

FIG. 12. The comparison of the actual precipitation response (solid line) and the predicted values (dashed line) $\nabla \cdot\left(\Delta q_{\mathrm{ctl}} /\right.$ $\Delta m_{\mathrm{ctl}} C F_{0}$ ) given $C=25 \%$ at $7^{\circ} \mathrm{S}$ in the idealized moist GCM as a function of maximum amplitude of forcing with $\mathrm{RH}_{\mathrm{SBM}}=70 \%$ (red), $\mathrm{RH}_{\mathrm{SBM}}=82 \%$ (green), and $\mathrm{RH}_{\mathrm{SBM}}=85 \%$ (blue; units are mm day ${ }^{-1}$ ).

latitudes where the local minima and maxima occur. Thus, one can predict the precipitation response by Eq. (7) given $C$ ( $25 \%$ in these experiments), which can be obtained from the EBM, and measures of the model tropics in the control run, $\Delta q_{\mathrm{ctl}}$ and $\Delta m_{\mathrm{ctl}}$.

Moreover, Eq. (7) can predict the sensitivity of precipitation response to the convection scheme. Figure 12 compares the change in the full model's precipitation and that predicted by Eq. (7) at a particular location, $7^{\circ} \mathrm{S}$, in simulations with different $\mathrm{RH}_{\mathrm{SBM}}$. The prediction captures the trend of increasing precipitation response with larger $\mathrm{RH}_{\mathrm{SBM}}$. Further analysis shows that the reason that Eq. (7) slightly overestimates the GCM response in all cases is mainly that the evaporation response is neglected.

Because $C$ and $\Delta q_{\mathrm{ctl}}$ are insensitive to $\mathrm{RH}_{\mathrm{SBM}}$, the theory of Eq. (7) implies that the increased response in the larger $\mathrm{RH}_{\mathrm{SBM}}$ cases results from the reduction in $\Delta m_{\mathrm{ctl}}$ in this simplified model. However, the prediction by Eq. (7) does not work well for the cases with $\mathrm{RH}_{\mathrm{SBM}}$ larger than $90 \%$, which display asymmetric response in the Hadley mass transport. Equation (5) works well for all cases but because Eq. (6) fails to predict the asymmetric mass transport response, the prediction by Eq. (7) does not work for cases with $\mathrm{RH}_{\mathrm{SBM}}$ larger than $90 \%$, although it does correctly suggest that the LSC-only case will generate the largest precipitation response. Similarly, as will be shown in section 5, in a comprehensive model in which the response is much larger and produces an asymmetric Hadley response about the

\section{Diffusion Coefficient}
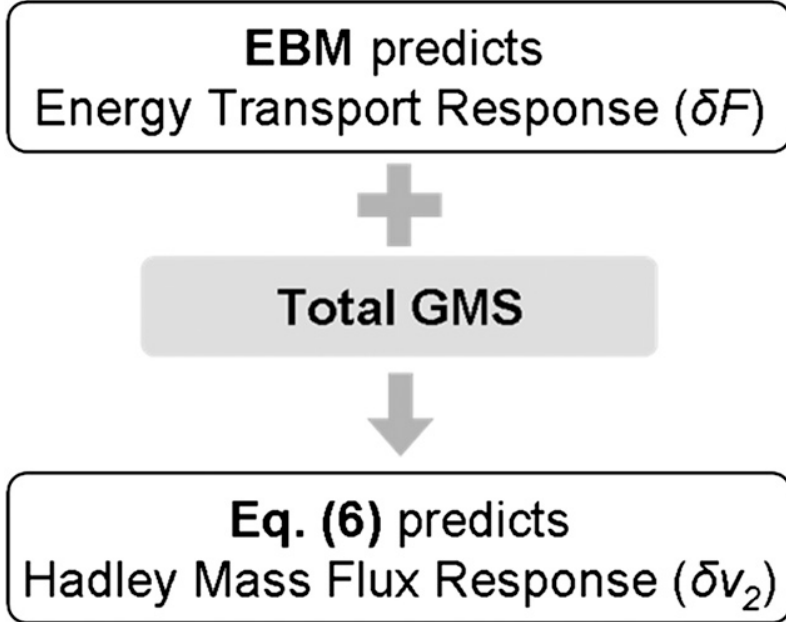

\section{Eq. (7) predicts Precipitation Response}

FIG. 13. The flowchart of the scheme [Eq. (7)] that predicts the precipitation response. Given the diffusion coefficient from the simplified GCM, EBM predicts the atmospheric energy transport response $(\delta F)$. The predicted $\delta F$ is converted to the Hadley mass flux response $\left(\delta v_{2}\right)$ using Eq. (6), given the total GMS from the GCM. Equation (7) can then fully predict the precipitation response.

equator, Eq. (7) cannot be used for quantitative prediction. The scheme [Eq. (7)] used to predict the precipitation response from the energy transport response is summarized in the flowchart in Fig. 13.

\section{Results for AM2}

In this section, we compare the results from the idealized moist GCM with the results from AM2 described in K08. In AM2, we vary the Tokioka parameter $\alpha$, which modifies the extent to which convection is inhibited in the model, by multiplying the standard value $\alpha$ by a factor of $0+, 1,2,4$, and 10 . The notation $0+$ refers to a model in which only the nonentraining deep convective plume is eliminated. Increasing $\alpha$ makes it more difficult for deep convection to occur, as described in section 2, and the fraction of large-scale condensation increases. Here, $A$ is set to be $60 \mathrm{~W} \mathrm{~m}^{-2}$, and we 
(a)

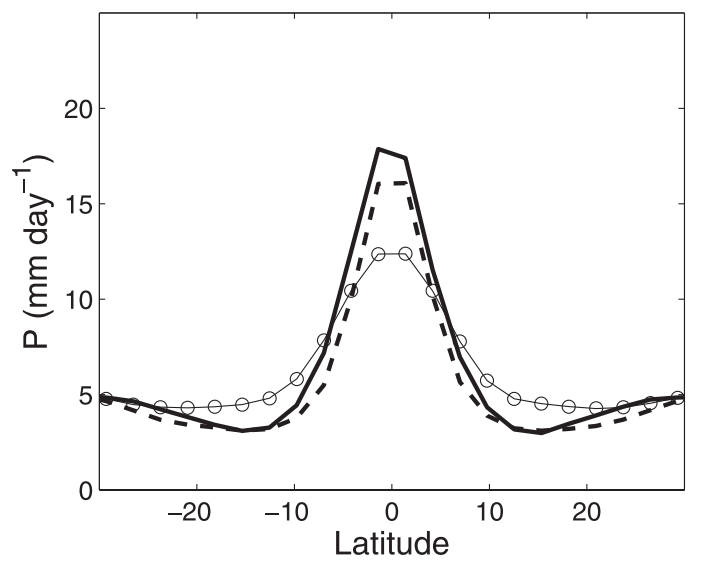

(c)

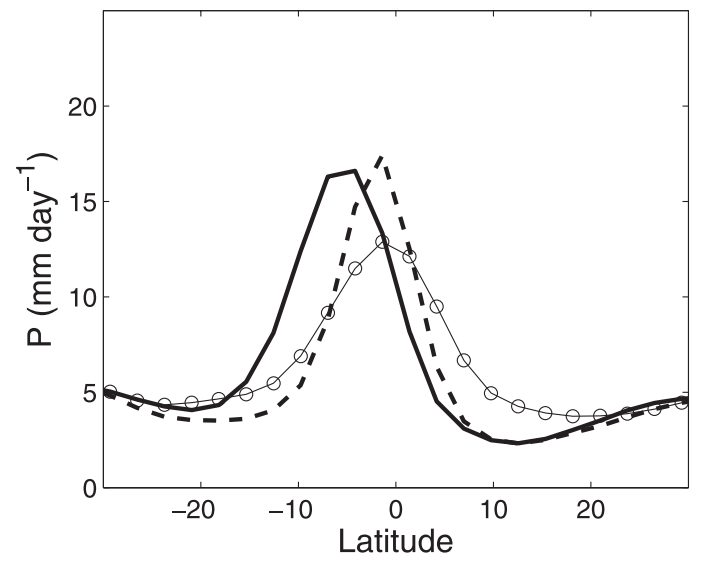

(b)

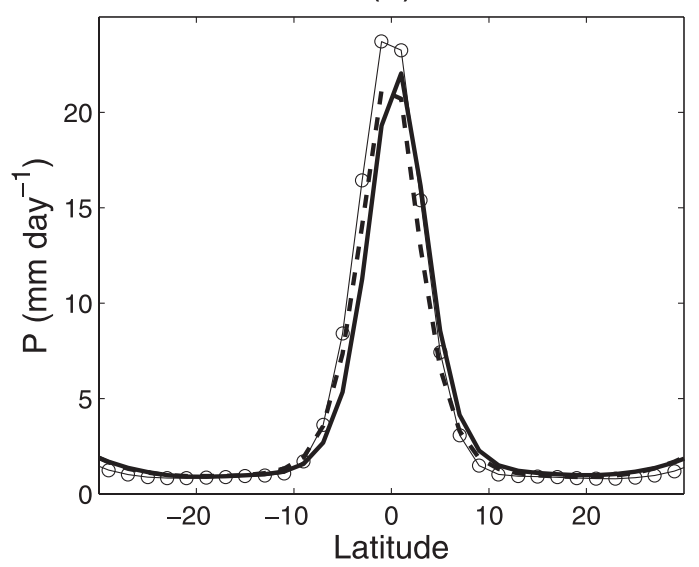

(d)

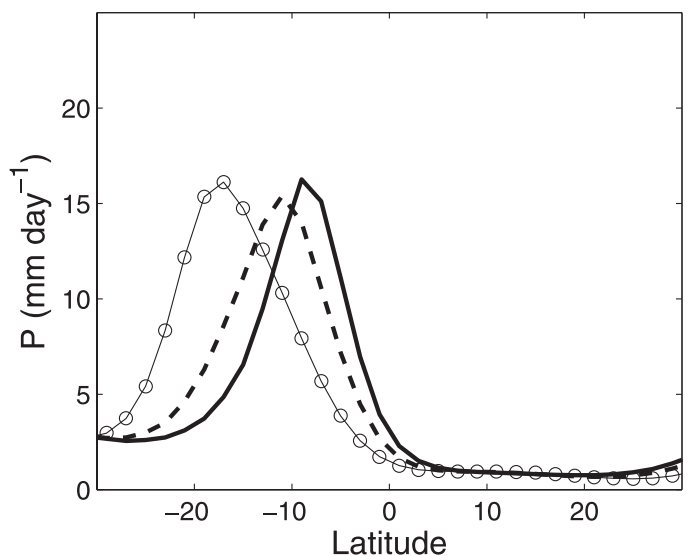

FIG. 14. Time mean, zonal mean precipitation $\left(\mathrm{mm} \mathrm{day}^{-1}\right)$ in the tropics in (a) the simplified moist GCM and (b) AM2 for the control runs $(A=0)$. (c),(d) Same as (a),(b) but for $A=60 \mathrm{~W} \mathrm{~m}^{-2}$. Panels (a) and (c) have values of $\mathrm{RH}_{\mathrm{SBM}}=70 \%$ (solid line with circles), $\mathrm{RH}_{\mathrm{SBM}}=85 \%$ (dashed line), and $\mathrm{RH}_{\mathrm{SBM}}=100 \%$ (solid line). Panels (b) and (d) values of $\alpha=1 \mathrm{X}$ (solid line with circles), $\alpha=4 \mathrm{X}$ (dashed line), and $\alpha=10 \mathrm{X}$ (solid line).

investigate how sensitive the response of the tropical precipitation is to the model's moist convection scheme in both models.

We plot the precipitation distribution with latitude for the control case with different values of $\mathrm{RH}_{\mathrm{SBM}}$ in the idealized model in Fig. 14a and that with different values of $\alpha$ in AM2 in Fig. 14b. Generally, compared with the simplified GCM, the ITCZ in AM2 is more peaked with greater precipitation at the equator and a smaller local minimum in the subtropics. It is interesting that altering the convection scheme parameter in AM2 does not affect the time-mean precipitation in the control climate substantially; however, in the idealized model, the ITCZ becomes sharper with $\mathrm{RH}_{\mathrm{SBM}}$, as discussed in section $3 b$.

Figures $14 \mathrm{c}$ and $14 \mathrm{~d}$ compare the precipitation response when the same forcing with $A=60$ is imposed in both models. In most of the cases, the precipitation re- sponse in AM2 is distinctively larger than in the simplified GCM. The smallest shift in AM2 when $\alpha=10 \mathrm{X}$ is comparable to the largest shift in the idealized model when $\mathrm{RH}_{\text {SBM }}=100 \%$. The tropical responses in AM2 can be understood from the degree of flux compensation $C$ shown in Fig. 15. Note that although the convection scheme is different in AM2 and the simplified GCM, the Tokioka parameter and $\mathrm{RH}_{\mathrm{SBM}}$ share the horizontal axis of Fig. 15 to allow for an easy comparison between the two models. This is because the Tokioka parameter and $\mathrm{RH}_{\mathrm{SBM}}$ represent qualitatively the same physical process; that is, their increase makes it harder for deep convection to occur in the respective model, resulting in an increase in the fraction of large-scale condensation. In all cases, $C$ in AM2 (black solid line) is significantly larger than that in the idealized model (gray solid line). This implies a larger change in energy fluxes in the tropics-hence, stronger Hadley mass transport 


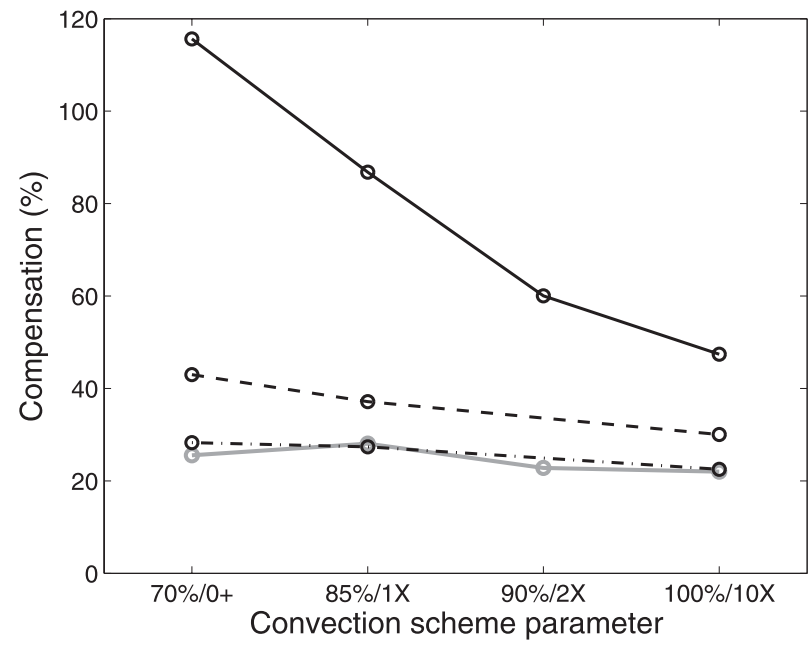

FIG. 15. Here, $C(\%)$ by the atmospheric energy flux averaged over $20^{\circ} \mathrm{S}$ and $20^{\circ} \mathrm{N}$ as a function of a convection scheme parameter $\left(\mathrm{RH}_{\mathrm{SBM}}\right.$ in the simplified moist GCM and Tokioka parameter $\alpha$ in AM2). Gray (black) solid line indicates the simplified moist GCM (AM2), and dashed (dashed-dotted) line indicates AM2 with prescribed clouds (and water vapor).

response in AM2-so a larger tropical precipitation response is expected compared with the idealized model. In response to an increase in the Tokioka parameter $\alpha$, $C$ decreases rapidly in AM2, which is responsible for the smaller change in tropical precipitation with $\alpha$ (as plotted in Fig. 14d), whereas $C$ stays nearly constant in the idealized model. As discussed in section $4 \mathrm{~b}$, in the idealized model, it is the change in the total gross moist stability, not $C$, that is responsible for the sensitivity shown in Fig. 14c.

K08 have shown that the reduction in $C$ with $\alpha$ in AM2 is due to changes in clouds, as confirmed by a prescribed cloud model. Although the cloud responses in AM2 are quite complex, as described in $\mathrm{K} 08$, the essence of the dependence of this response on $\alpha$ is related to the fact that enhanced convection reduces low cloud amount in AM2. Consistent with the importance of cloud feedback in this model, the sensitivity of $C$ to $\alpha$ is reduced by prescribing clouds (dashed line in Fig. 15).

The remaining difference in the degree of compensation between AM2 and the idealized model can be attributed to water vapor feedbacks. In the idealized model, long-wave optical depth is a prescribed function, so changes in water vapor content do not feed back on radiative fluxes. However, water vapor feedback is expected to amplify the imposed extratropical thermal forcing. For instance, increases in water vapor content in the Southern Hemisphere high latitudes should reinforce the heat source present there. To quantify this

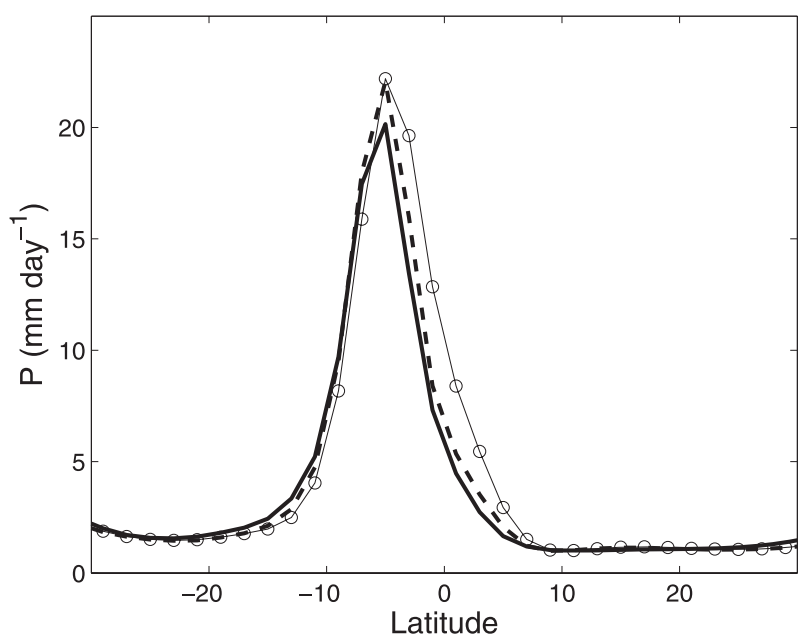

FIG. 16. Time mean, zonal mean precipitation $\left(\mathrm{mm} \mathrm{day}^{-1}\right)$ in the tropics in AM2 with prescribed clouds and water vapor for $A=$ $60 \mathrm{~W} \mathrm{~m}^{-2}$ with $\alpha=0+$ (solid lines with circles), $\alpha=1 \mathrm{X}$ (dashed line), and $\alpha=10 \mathrm{X}$ (solid line).

effect, we fix the water vapor content in the radiation calculation in addition to the cloud distribution. The dashed-dotted line in Fig. 15 shows $C$ from the models with prescribed water vapor and clouds. In this case, $C$ is further reduced to have a similar magnitude to that of the idealized model, which has no clouds or water vapor feedbacks. Because $C$ becomes insensitive to $\alpha$ in AM2 with prescribed clouds and water vapor, the large sensitivity to convection scheme parameters of the precipitation response in the tropics in AM2 also disappears in simulations with fixed clouds and water vapor, as shown in Fig. 16.

Because $C$ in AM2 with prescribed clouds and water vapor is consistent with $C$ in the simplified model with gray radiation, the low level of compensation of about $25 \%$ seems to be dynamically controlled through eddy energy fluxes, as discussed in section $3 \mathrm{a}$ and summarized in Fig. 6. The remainder is feedback controlled, with the cloud feedback portion likely being model dependent.

\section{Conclusions}

The response of tropical precipitation to extratropical heating and cooling is investigated using an idealized moist GCM where clouds and water vapor feedbacks are eliminated. The experimental configuration is the same as in $\mathrm{K} 08$; that is, an aquaplanet GCM coupled to a slab ocean is perturbed by an imposed cross-equatorial oceanic flux. In response to extratropical forcing, the distribution of precipitation becomes more skewed to the warmer hemisphere, and the ITCZ displacement increases with the amplitude of the forcing. 
This response in tropical precipitation is found to increase as the convection scheme parameter $\mathrm{RH}_{\mathrm{SBM}}$ increases, increasing the inhibition of moist convection in the model.

As an intermediate step in understanding these tropical responses, we focus on the degree of compensation $C$ between the imposed oceanic flux and the resulting response in the atmospheric energy transport. Here, $C$ can be converted into a change in mass flux, given the total gross moist stability of the control climate, and this leads to a theory for precipitation response, given $C$; that is, the larger the degree of compensation, the greater the change in mass fluxes, leading to a larger tropical precipitation response. The idealized model produces a low level of compensation of about $25 \%$ regardless of the convection scheme parameter and the amplitude of the imposed forcing. This low value can be obtained from a diffusive energy balance model with fixed diffusivity. This idealized model provides confirmation that there is no fundamental dynamical reason why the atmospheric transport should closely compensate an imposed change in oceanic transport.

The degree of compensation is about 3 times higher in the standard configuration of a comprehensive model AM2 than in the idealized GCM, and this degree of compensation varies from $47 \%$ to $115 \%$ by altering the convection scheme in the model. The larger degree of compensation is responsible for a distinctively greater ITCZ shift in AM2. In AM2 both cloud responses and water vapor feedbacks act as a positive feedback to amplify the imposed forcing. The presence or absence of these feedbacks is the primary differences between the two models. This claim is supported by AM2 simulations with prescribed clouds and water vapor that show significantly less change in tropical precipitation. In fact, a similar degree of compensation $C$ to that in the idealized model is obtained in AM2 with prescribed clouds and water vapor. Thus, we believe the response in the atmospheric energy transport in the tropics is the natural starting point to understanding the magnitude of the tropical precipitation response.

Although the response in the atmospheric energy transport, or $C$, in the simplified GCM is insensitive to the convection scheme parameter $\mathrm{RH}_{\mathrm{SBM}}$, the magnitude of the tropical precipitation response increases with $\mathrm{RH}_{\mathrm{SBM}}$. This differs from AM2 in that changes in the magnitude of the tropical precipitation response resulting from altered convection scheme parameter in AM2 are primarily driven by changes in compensation.

The tropical responses in the idealized model can be understood using the simple theory developed in this study, which incorporates the compensation $C$ and two measures from the control climate: the total gross moisture stratification and the total gross moist stability. The implication is that the reduced total gross moist stability with increasing $\mathrm{RH}_{\mathrm{SBM}}$ is responsible for the larger changes in mass transport and for the greater tropical precipitation response to the extratropical thermal forcing. In this model, the atmospheric energy transport in the control climate varies little with $\mathrm{RH}_{\mathrm{SBM}}$ but the total gross moist stability changes associated with changes in the Hadley circulation strength: the case with stronger Hadley circulation in the control climate (larger $\mathrm{RH}_{\mathrm{SBM}}$ ) exhibits smaller total gross moist stability, indicating less efficient Hadley circulation in transporting energy poleward. However, because this theory predicts the mass flux response and the precipitation response to be antisymmetric about the equator by construction, it fails to predict the spatial structure for cases in which the mass flux response is large enough that it loses this antisymmetric structure.

\section{REFERENCES}

Anderson, J. L., and Coauthors, 2004: The new GFDL global atmosphere and land model AM2-LM2: Evaluation with prescribed SST simulations. J. Climate, 17, 4641-4673.

Arakawa, A., and W. H. Schubert, 1974: Interaction of a cumulus cloud ensemble with the large-scale environment. Part I. J. Atmos. Sci., 31, 674-701.

Betts, A. K., 1986: A new convective adjustment scheme. Part I: Observational and theoretical basis. Quart. J. Roy. Meteor. Soc., 112, 677-691.

_ , and M. J. Miller, 1986: A new convective adjustment scheme. Part II: Single column tests using GATE wave, BOMEX, and arctic air-mass data sets. Quart. J. Roy. Meteor. Soc., 112, 693-709.

Bretherton, C. S., and A. H. Sobel, 2002: A simple model of a convectively coupled Walker circulation using the weak temperature gradient approximation. J. Climate, 15, 29072920.

Broccoli, A. J., K. A. Dahl, and R. J. Stouffer, 2006: Response of the ITCZ to Northern Hemisphere cooling. Geophys. Res. Lett., 33, L01702, doi:10.1029/2005GL024546.

Chiang, J. C. H., and C. M. Bitz, 2005: Influence of high latitude ice cover on the marine intertropical convergence zone. Climate Dyn., 25, 477-496.

Chou, C., and J. D. Neelin, 2004: Mechanisms of global warming impacts on regional tropical precipitation. J. Climate, 17, 2688-2701.

—, , J.-Y. Tu, and C.-T. Chen, 2006: Regional tropical precipitation change mechanisms in ECHAM4/OPYC3 under global warming. J. Climate, 19, 4207-4223.

Emanuel, K. A., J. D. Neelin, and C. S. Bretherton, 1994: On largescale circulations in convecting atmospheres. Quart. J. Roy. Meteor. Soc., 120, 1111-1143.

Frierson, D. M. W., 2007a: The dynamics of idealized convection schemes and their effect on the zonally averaged tropical circulation. J. Atmos. Sci., 64, 1959-1976.

- , 2007b: Convectively coupled Kelvin waves in an idealized moist general circulation model. J. Atmos. Sci., 64, 20762090. 
- A. J. Majda, and O. M. Pauluis, 2004: Large scale dynamics of precipitation fronts in the tropical atmosphere: A novel relaxation limit. Commun. Math. Sci., 2, 591-626.

—, I. M. Held, and P. Zurita-Gotor, 2006: A gray-radiation aquaplanet moist GCM. Part I: Static stability and eddy scale. J. Atmos. Sci., 63, 2548-2566.

,$- \ldots$, and - 2007: A gray-radiation aquaplanet moist GCM. Part II: Energy transports in altered climates. J. Atmos Sci., 64, 1680-1693.

Held, I. M., 2005: The gap between simulation and understanding in climate modeling. Bull. Amer. Meteor. Soc., 86, 1609-1614.

—, M. Zhao, and B. Wyman, 2007: Dynamic radiative-convective equilibria using GCM column physics. J. Atmos. Sci., 64, 228-238.

Hughen, K. A., J. R. Southon, S. J. Lehman, and J. T. Overpeck, 2000: Synchronous radiocarbon and climate shifts during the last deglaciation. Science, 290, 1951-1954.

Kang, S. M., I. M. Held, D. M. W. Frierson, and M. Zhao, 2008: The response of the ITCZ to extratropical thermal forcing: Idealized slab-ocean experiments with a GCM. J. Climate, 21, 3521-3532.

Lynch-Stieglitz, J., 2004: Hemispheric asynchrony of abrupt climate change. Science, 304, 1919-1920.

Moorthi, S., and M. J. Suarez, 1992: Relaxed Arakawa-Schubert: A parameterization of moist convection for general circulation models. Mon. Wea. Rev., 120, 978-1002.

Neelin, J. D., 2007: Moist dynamics of tropical convection zones in monsoons, teleconnections, and global warming. The Global Circulation of the Atmosphere, T. Schneider and A. Sobel, Eds., Princeton University Press, 267-301.

- , and I. M. Held, 1987: Modeling tropical convergence based on the moist static energy budget. Mon. Wea. Rev., 115, 3-12.

_ , and J.-Y. Yu, 1994: Modes of tropical variability under convective adjustment and the Madden-Julian oscillation. Part I: Analytical theory. J. Atmos. Sci., 51, 1876-1894.
, and H. Su, 2005: Moist teleconnection mechanisms for the tropical South American and Atlantic sector. J. Climate, 18, 3928-3950.

— I. M. Held, and K. H. Cook, 1987: Evaporation-wind feedback and low-frequency variability in the tropical atmosphere. J. Atmos. Sci., 44, 2341-2348.

Peterson, L. C., G. H. Haug, K. A. Hughen, and U. Röhl, 2000: Rapid changes in the hydrologic cycle of the tropical Atlantic during the last glacial. Science, 290, 1947-1951.

Sellers, W. D., 1969: A global climatic model based on the energy balance of the earth-atmosphere system. J. Appl. Meteor., 8, 392-400.

Sobel, A. H., J. Nilsson, and L. M. Polvani, 2001: The weak temperature gradient approximation and balanced tropical moisture waves. J. Atmos. Sci., 58, 3650-3655.

Stouffer, R. J., and Coauthors, 2006: Investigating the causes of the response of the thermohaline circulation to past and future climate changes. J. Climate, 19, 1365-1387.

Tokioka, T., K. Yamazaki, A. Kitoh, and T. Ose, 1988: The equatorial 30-60 day oscillation and the Arakawa-Schubert penetrative cumulus parameterization. J. Meteor. Soc. Japan, 66, 883-901.

Wang, X., A. S. Auler, R. L. Edwards, H. Cheng, P. S. Cristallli, P. L. Smart, D. A. Richards, and C.-C. Shen, 2004: Wet periods in northeastern Brazil over the past $210 \mathrm{kyr}$ linked to distant climate anomalies. Nature, 432, 740-743.

Yano, J.-I., and M. Bonazzola, 2009: Scale analysis for the largescale tropical atmospheric dynamics. J. Atmos. Sci., 66, 159-172.

Yoshimori, M., and A. J. Broccoli, 2008: Equilibrium response of an atmosphere-mixed layer ocean model to different radiative forcing agents: Global and zonal mean response. J. Climate, 21, 4399-4423.

Zhang, R., and T. L. Delworth, 2005: Simulated tropical response to a substantial weakening of the Atlantic thermohaline circulation. J. Climate, 18, 1853-1860. 